\title{
Photodegradation of levofloxacin in aqueous and organic solvents: A kinetic study
}

\author{
IQBAL AHMAD ${ }^{1}$ \\ RAHEELA BANO ${ }^{1}$ \\ MUHAMMAD ALI SHERAZ ${ }^{1}$ \\ SOFIA AHMED 1 \\ TANIA MIRZA ${ }^{1}$ \\ SHAKEEL AHMAD ANSARI ${ }^{2}$ \\ ${ }^{1}$ Institute of Pharmaceutical Sciences \\ Baqai Medical University, Karachi 74600 \\ Pakistan \\ 2 Tabros Pharma, Karachi 74600, Pakistan
}

The kinetics of photodegradation of levofloxacin in solution on UV irradiation in the $\mathrm{pH}$ range $2.0-12.0$ has been studied using a HPLC method. Levofloxacin undergoes first-order kinetics in the initial stages of the reaction and the apparent first-order rate constants are of the order of 0.167 to $1.807 \times 10^{-3} \mathrm{~min}^{-1}$. The rate-pH profile is represented by a curve indicating the presence of cationic, dipolar and anionic species during the reaction. The singly ionized form of the molecule is non-fluorescent and is less susceptible to photodegradation. The increase in the degradation rate in the $\mathrm{pH}$ range 5.0-9.0 may be due to greater reactivity of the ionized species existing in that range. The rate appears to vary with a change in the degree of ionization of the species present in a particular $\mathrm{pH}$ range and their susceptibility to photodegradation. Above $\mathrm{pH} 9$, the decrease in the rate of photodegradation may be a result of deprotonation of the piperazinyl group. The levofloxacin molecule is more stable in the $\mathrm{pH}$ range around 7, which is then suitable for formulation purposes. The photodegradation of levofloxacin was found to be affected by the dielectric constant and viscosity of the medium.

Keywords: levofloxacin, photodegradation, kinetics, solvent effect

Levofloxacin hemihydrate [(-)-(S)-9-fluoro-2,3-dihydro-3-methyl-10(4-methyl-1-piperazinyl)-7-oxo-7H-pyrido[1,2,3-de]-1,4-benzoxazine-6-carboxylic acid] (Fig. 1) is a broad spectrum fluoroquinolone antibacterial, which is effective against a wide range of Gram-positive and Gram-negative bacteria (1). Fluoroquinolones are sensitive to light (2) and studies have been carried out on the photodegradation of quinolones (3), fluoroquinolones (4), ciprofloxacin $(5,6)$, sparfloxacin (7), moxifloxacin (8) and fluoroquinolone carboxylic acids $(9,10)$. Some quinolones are phototoxic and induce photosensitized hemolysis of erythrocytes (11). It has been reported that the photoproducts of sparfloxacin exhibit low activity (7). A photodegradation study of levofloxacin has been reported and

\footnotetext{
* Correspondence; e-mail: ali_sheraz80@hotmail.com
} 
some degradation products have been identified (12). Quinolones such as ciprofloxacin, norfloxacin and nalidixic acid undergo photodegradation by first-order kinetics (7). The same behavior has been observed in the photodegradation of levofloxacin in aqueous and organic solvents. Commercial preparations of levofloxacin are available in the form of injectables and eye drops. In the present work, the kinetics of photodegradation of levofloxacin over a wide range of $\mathrm{pH}$ values was studied and the rate- $\mathrm{pH}$ profile for the drug was set. The effect of solvent dielectric constant and viscosity on the rate of photodegradation of levofloxacin has been also studied.

\section{EXPERIMENTAL}

Levofloxacin (99\%) was kindly donated by Tabros Pharma (Pakistan) and was used without further purification. Acetonitrile and methanol were of HPLC grade and were obtained from Merck (Germany). All other solvents and reagents were of analytical grade and were obtained from Sigma (USA). Water was purified with a Milli-Q Millipore system (USA). The solvents and solutions were filtered through a Millipore filtration unit and degassed before use. The following buffer systems were used throughout: $\mathrm{KCl} / \mathrm{HCl}(\mathrm{pH}$ 1.0-2.0), citric acid/ $\mathrm{Na}_{2} \mathrm{HPO}_{4}(\mathrm{pH} 2.5-8.0), \mathrm{Na}_{2} \mathrm{~B}_{4} \mathrm{O}_{7} / \mathrm{HCl}\left(\mathrm{pH}\right.$ 8.5-9.0), $\mathrm{Na}_{2} \mathrm{~B}_{4} \mathrm{O}_{7} / \mathrm{NaOH}$ ( $\mathrm{pH}$ 9.5-10.5), $\mathrm{Na}_{2} \mathrm{HPO}_{4} / \mathrm{NaOH}(\mathrm{pH} 11.0-12.0)$. Ionic strength was set $0.02 \mathrm{~mol} \mathrm{~L}^{-1}$ in each case.

\section{Precaution}

The experimental work was carried out in a dark chamber under subdued light. Levofloxacin solutions were protected from light before irradiation. Freshly prepared solutions of the drug were used for each experiment to avoid the effect of any chemical or photochemical change.

\section{HPLC assay}

The HPLC assay of levofloxacin was carried out by the method of Santoro et al. (13). The HPLC system consisted of a high-pressure liquid chromatograph, model Shimadzu LC-9A (Japan) equipped with a UV-detector model spp-6A connected to a microcomputer system. The analytical column used was a $100 \mathrm{RP}-18$ column $(25 \mathrm{~cm} \times 0.46 \mathrm{~cm}, 5$ $\mu \mathrm{m})$. The HPLC analysis was carried out at room temperature $\left(25 \pm 2{ }^{\circ} \mathrm{C}\right)$ using isocratic conditions. The mobile phase consisted of a mixture of water and acetonitrile (80:20, $V / V$ ) with $0.3 \%$ triethylamine at $\mathrm{pH} 3.3$ adjusted with phosphoric acid. The flow rate was $1.0 \mathrm{~mL} \mathrm{~min}^{-1}$ and the volume of injection was $20 \mu \mathrm{L}$. All the solutions and the mobile phase were sonicated for 20-25 min before use. The detection of levofloxacin was carried out at $287 \mathrm{~nm}$. The method was validated before its application to the assay of levofloxacin in photodegraded solutions. 


\section{Photolysis}

A $5 \times 10^{-4} \mathrm{~mol} \mathrm{~L}^{-1}$ aqueous solution of levofloxacin was prepared and the $\mathrm{pH}$ was adjusted in the range of 2.0-12.0 with an appropriate buffer solution. The solution was placed in a $100 \mathrm{~mL}$ beaker (Pyrex, France), immersed in a water bath maintained at $25 \pm 1{ }^{\circ} \mathrm{C}$ and irradiated in a dark chamber using a Philips $30 \mathrm{~W}$ TUB tube (The Netherlands) (87\% emission at $287 \mathrm{~nm}$, the absorption maximum of levofloxacin), fixed horizontally at a distance of $30 \mathrm{~cm}$ from the centre of the vessel. Samples were withdrawn at appropriate intervals for the chromatographic assay.

\section{Light intensity measurement}

The intensity of the Philips $30 \mathrm{~W}$ TUV tube was determined by potassium ferrioxalate actinometry (14) as $3.85 \pm 0.12 \times 10^{-3} \mathrm{~kJ}$.

\section{RESULTS AND DISCUSSION}

\section{Assay of levofloxacin}

Levofloxacin was assayed by HPLC in pure and photolysed solutions. Determination of levofloxacin in degraded solutions was carried out with reference to a calibration curve $\left(4.0-24.0 \mu \mathrm{g} \mathrm{mL}^{-1}\right)$. The calibration curve was prepared by injecting levofloxacin solutions in triplicate and plotting the mean value of peak area vs. concentration. This resulted in the least-squares regression equation with $R^{2}=0.9992$.

\section{Kinetics of photodegradation}

The apparent first-order rate constants $\left(k_{\mathrm{obs}}\right)$ for the photodegradation of levofloxacin at $\mathrm{pH} 2.0-12.0$ are in the range of $0.167(\mathrm{pH} 2.0)$ to $1.807 \times 10^{-3} \mathrm{~min}^{-1}$ ( $\mathrm{pH} 10.0$ ). The least squares correlation coefficients are 0.996-0.999. The rate constants indicate the existence of specific ionic species of the molecule undergoing degradation, as discussed in the next section. The values of rate constants depend on the experimental conditions, including light intensity.

\section{Mode of photodegradation}

The photodegradation of levofloxacin leads to the formation of several products (12). It has been suggested that the photodegradation of quinolones in aqueous solution proceeds in two steps. It involves the degradation of the piperazine substitution to form 7-amine derivatives, followed by degradation to $\mathrm{CO}_{2}$ and intermediate polar compounds (3). Photodegradation of fluoroquinolones in aqueous solution gives rise to pyridone dicarboxylic and tricarboxylic acids through polar intermediates by several pathways $(9,10)$. Our studies support the previous finding (3) indicating the influence of the solvent dielectric constant on the rate of photodegradation of levofloxacin involving polar intermediates. 
<smiles>CC1COc2c(N3CCN(C)CC3)c(F)cc3c(=O)c(C(=O)O)cn1c23</smiles>

Fig. 1. Structure of levofloxacin.

The degradation of these intermediates is enhanced by an increase in the polarity of the medium, as observed in aqueous and organic solvents.

Effect of $\mathrm{pH}$ on photodegradation. - Levofloxacin exists as a zwitter ion in the $\mathrm{pH}$ range 6.0-7.5 and the two $\mathrm{p} K_{\mathrm{a}}$ values (5.59 and 7.94) are very close to the isoelectric point (6.77) (15). The molecule undergoes several acid-base equilibria (16) to form cationic, dipolar and anionic species with a change in $\mathrm{pH}$. This is evident from the loss of fluorescence of singly ionized species in acid and alkaline regions (17). The rate of photodegradation of levofloxacin in aqueous solution depends upon the reactivity of the specific ionic species existing in a particular $\mathrm{pH}$ range. The rate- $\mathrm{pH}$ profile for the degradation of levofloxacin is a curve showing a rise with $\mathrm{pH}$ that indicates the effect of ionization on the reaction rate (Fig. 2). The profile presents a combination effect of different ionized forms of the molecule and their relative susceptibility to photodegradation. There is an inflection point at $\mathrm{pH}$ value near $\mathrm{pK} K_{\mathrm{a} 1}$ (5.59), indicating that the dissociation equilibrium of carboxylic acid group affects the rate of degradation. Under the same conditions, the protonated piperazinyl group may also influence the rate of degradation. Another inflection point around $\mathrm{pH} 8$ is a result of partial deprotonation of the piperazinyl group $\left(\mathrm{p} K_{\mathrm{a} 2}\right.$ 7.94). Above $\mathrm{pH}$, the decrease in the rate of degradation may account for the presence of the non-protonataed form of the molecule. Degradation of levofloxacin is about two times faster at $\mathrm{pH} 10$ compared to that at $\mathrm{pH} 7$ and this is in agreement with the observation of De Witte (18). The rate-pH profile of levofloxacin is similar to that of riboflavin, which

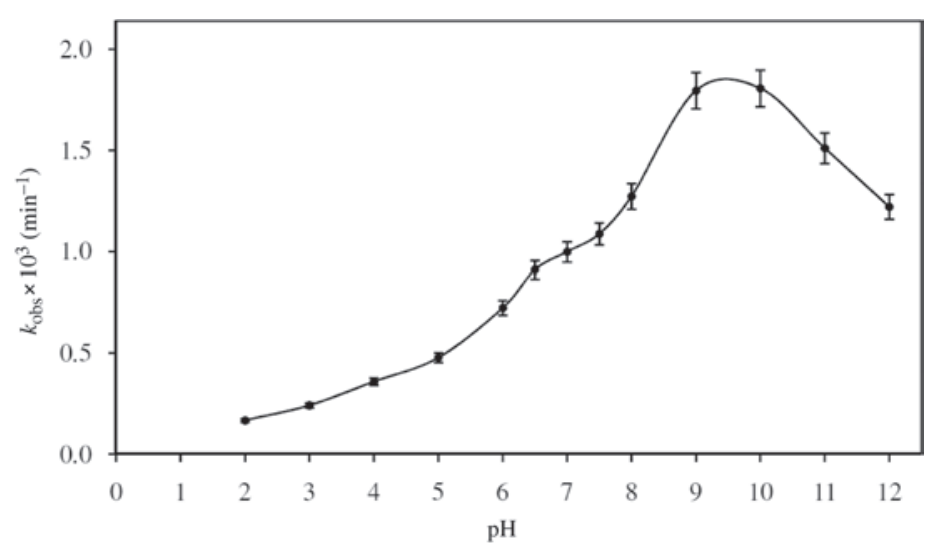

Fig. 2. $k_{\mathrm{obs}}-\mathrm{pH}$ profile for the photodegradation of levofloxacin in aqueous solution. 
Table I. Apparent first-order rate constant $\left(\mathrm{k}_{\text {obs }}\right)$ for the photodegradation of levofloxacin in water and organic solvents

\begin{tabular}{lccc}
\hline Solvent & $\begin{array}{c}\text { Dielectric constant } \\
\left(25^{\circ} \mathrm{C}\right)\end{array}$ & $\begin{array}{c}\text { Inverse viscosity } \\
(\mathrm{mPa} \mathrm{s})^{-1}\end{array}$ & $k_{\mathrm{obs}} \times 10^{4}\left(\mathrm{~min}^{-1}\right)^{\mathrm{a}}$ \\
\hline Water (pH 7.0) & 78.5 & 1.00 & $9.98 \pm 0.35$ \\
Acetonitrile & 38.5 & 2.898 & $7.66 \pm 0.31$ \\
Methanol & 32.6 & 1.838 & $7.14 \pm 0.33$ \\
Ethanol & 24.3 & 0.931 & $6.80 \pm 0.23$ \\
1-Propanol & 20.1 & 0.514 & $6.32 \pm 0.27$ \\
1-Butanol & 17.8 & 0.387 & $6.16 \pm 0.20$ \\
\hline
\end{tabular}

${ }^{a}$ Mean $\pm \mathrm{SD}, n=3$.

also exhibits the effect of the protonation equilibria of the dipolar molecule on the rate of photodegradation (19). The $\mathrm{pH}$ range 5-7 may be considered useful for the formulation of liquid preparations of levofloxacin.

Effect of the solvent. - The present study also involves the photodegradation of levofloxacin in aqueous and organic solvents and the apparent first-order rate constants $\left(k_{\text {obs }}\right)$ for the reactions are reported in Table I. The plot of $k_{\text {obs }} v s$. the solvent dielectric constant is linear $\left(R^{2}=0.992\right)$, indicating the presence of a polar intermediate in the reaction pathway, as observed in the case of the photolysis of flavins in organic solvents (20). Solvent interaction would determine the degree of forward reaction as evident from the change in $k_{\text {obs }}$ with the solvent dielectric constant. A linear relation was also been observed between $k_{\text {obs }}$ and the inverse of solvent viscosity $\left(R^{2}=0.965\right)$, suggesting that the reactivity of the excited triplet state would be affected by the viscosity of the medium as a result of the diffusion controlled processes. However, this relation is not followed by water, probably due to the difference in the mode of degradation of levofloxacin in aqueous and organic solvents affecting the rates of reaction. These observations indicate that both the solvent dielectric constant and viscosity influence the rate of photodegradation of levofloxacin. The reaction is facilitated in a polar medium and is hindered by the solvent viscosity. The kinetic data indicate that the photodegradation of levofloxacin is greater in aqueous solution compared to that of organic solvents as a result of the effect of solvent characteristics.

\section{CONCLUSIONS}

The photodegradation of levofloxacin in the $\mathrm{pH}$ range $2.0-12.0$ is represented by a rate-pH profile that indicates the presence of different ionic species undergoing the reaction. The cationic and anionic species of the molecule appear to be less susceptible to degradation whereas the intermediate dipolar species is more susceptible to degradation. The rate of the reaction depends on the degree of ionization of the dipolar species in the $\mathrm{pH}$ range 5.0-9.0. These species may give rise to a more reactive excited triplet 
state that would readily lead to the formation of degradation products. Cationic and anionic species undergo slow degradation due to acid-base quenching of the excited singlet state. Solvent characteristics such as the dielectric constant and viscosity have been found to affect the rate of photodegradation linearly.

\section{REFERENCES}

1. D. E. King, R. Malone and S. H. Lilley, New classification and update on the quinolone antibiotics, Am. Fam. Physician 61 (2000) 2741-2748.

2. K. Kummerer, Antibiotics in the aquatic environment-A review, Part 1, Chemosphere 75 (2009) 417-434; DOI: 10.1016/j.bbr.2011.03.031.

3. J. Burhenne, M. Ludwig and M. Spiteller, Polar photodegradation products of quinolones determined by HPLC/MS/MS, Chemosphere 38 (1999) 1279-1286; DOI: 10.1016/j.bbr.2011.03.031.

4. M. Budai, P. Grof, A. Zimmer, K. Papai, I. Klebovich and K. Ludanyi, UV light induced photodegradation of liposome encapsulated fluoroquinolones: An MS study, J. Photochem. Photobiol. A: Chem. 198 (2008) 268-273; DOI: 10.1016/j.jphotochem.2008.04.004.

5. E. M. Tiefenbacher, E. Haen, B. Przybilla and H. Kurz, Photodegradation of some quinolones used as antimicrobial therapeutics, J. Pharm. Sci. 83 (1994) 463-467; DOI: 10.1002/jps.2600830403.

6. K. Torniainen, S. Tammilehto and V. Ulvi, The effect of $\mathrm{pH}$, buffer type and drug concentration on the photodegradation of ciprofloxacin, Int. J. Pharm. 132 (1996) 53-61; DOI: 10.1016/j.bbr.2011.03.031.

7. H. R. N. Salgado, P. R. H. Moreno, A. L. Braga and E. E. S. Schapoval, Photodegradation of sparfloxacin and isolation of its degradation products by preparative HPLC, Rev. Cienc. Farm. Basica Apl. 26 (2005) 47-54.

8. H. Hubicka, J. Krzek, B. Zuromska, M. Walczak, M. Zylewski and D. Pawlowski, Determination of photostability and photodegradation products of moxifloxacin in the presence of metal ions in solutions and solid phase. Kinetics and identification of photoproducts, Photochem. Photobiol. 11 (2012) 351-357; DOI: 10.1039/c1pp05259d.

9. J. Burhenne, M. Ludwig, P. Nikoloudis and M. Spiteller, Photolytic degradation of fluoroquinolone carboxylic acids in aqueous solution. Part I: Primary photoproducts and half-lives, Environ. Sci. Pollut. Res. 4 (1997) 10-15; DOI: 10.1007/BF02986278.

10. J. Burhenne, M. Ludwig and M. Spiteller, Photolytic degradation of fluoroquinolone carboxylic acids in aqueous solution. Part II: Isolation and structural elucidation of polar photometabolities, Environ. Sci. Pollut. Res. 4 (1997) 61-67; DOI: 10.1007/BF02986278.

11. G. Viola, L. Facciolo, M. Canton, D. Vedaldi, F. Dall Acqua, G. G. Aloisi, M. Amelia, A. Barbafina, F. Elisei and L. Latterini, Photophysical and phototoxic properties of the antibacterial fluoroquinolones levofloxacin and moxifloxacin, Chem. Biodivers. 1 (2004) 782-801; DOI: 10.1002/ cbdv.200490061.

12. Y. Yoshida, E. Sato and R. Moroi, Photodegradation products of levofloxacin in aqueous solution, Arzneim. Forsch. 43 (1993) 601-606.

13. M. R. M. Santoro, N. M. Kassab, A. K. Singh and E. R. M. Kedor-Hackmam, Quantitative determination of gatifloxacin, levofloxacin, lomefloxacin and pefloxacin fluoroquinolonic antibiotics in pharmaceutical preparations by high-performance liquid chromatography, J. Pharm. Biomed. Anal. 40 (2006) 179-184; DOI: 10.1016/j.jpba.2005.06.018.

14. C. G. Hatchard and C. A. Parker, A new sensitive chemical actinometer. II. Potassium ferrioxalate as a standard chemical actinometer, Proc. Royal Soc. (London) A 235 (1956) 518-536; DOI: 10.1098/rspa.1956.0102. 
15. B. K. Singh, D. V. Parwate and S. K. Shukla, Rapid color test identification system for screening of counterfeit fluoroquinolones, E-J. Chem. 6 (2009) 377-384; DOI: 10.1155/2009/870286.

16. M. T. Montero, D. Saiz, R. Sitges, J. L. Vazquez and J. H. Borrell, Influence of physicochemical properties of fluoroquinolones on encapsulation efficiency in liposomes, Int. J. Pharm. 138 (1996) 113-120; DOI: 10.1016/0378-5173(96)04543-7.

17. J. A. O. Gonzalez, M. C. Mochon and F. J. B. de la Rosa, Spectrofluorimetric determination of levofloxacin in tablets, human urine and serum, Talanta 52 (2000) 1149-1156; DOI: 10.1016/S0039-9140(00)00484-7.

18. B. De Witte, H. V. Langenhove, K. Hemelsoet, K. Demeestere, P. De Wispelaere, V. V. Speybroeck and J. Dewulf, Levofloxacin ozonation in water: Rate determining process parameters and reaction pathway elucidation, Chemosphere 76 (2009) 683-689; DOI: 10.1016/j.bbr.2011.03.031.

19. I. Ahmad, Q. Fasihullah, A. Noor, I. A. Ansari and Q. N. M. Ali, Photolysis of riboflavin in aqueous solution: a kinetic study, Int. J. Pharm. 280 (2004) 199-208; DOI: 10.1016/j.ijpharm.2004.05.020.

20. I. Ahmad and G. Tollin, Solvent effects on flavin electron transfer reactions, Biochemistry 20 (1981) 5925-5928; DOI: 10.1021/bi00523a042. 